\title{
Hemostatic effects of tranexamic acid in elective thoracic aortic surgery: A prospective, randomized, double-blind, placebo-controlled study
}

\author{
Valter Casati, MD \\ Luca Sandrelli, MD \\ Giovanni Speziali, MD \\ Giliola Calori, MD ${ }^{\mathrm{c}}$ \\ Maria Antonietta Grasso, MD \\ Salvatore Spagnolo, MD ${ }^{\mathrm{b}}$
}

Objective: We studied the hemostatic effects of tranexamic acid in patients undergoing elective surgery involving the thoracic aorta.

Methods: In a double-blind, randomized fashion, 60 consecutive patients were assigned to two treatment groups: 30 patients (placebo group) received infusion of saline solution, and 30 (treatment group) received tranexamic acid (1 g before skin incision, an infusion of $400 \mathrm{mg} / \mathrm{h}$ during the operation, and $500 \mathrm{mg}$ in the pump priming). Perioperative bleeding was considered as a primary outcome. Perioperative allogeneic transfusions, major thrombotic complications (myocardial infarction, pulmonary embolism, renal insufficiency), and surgical outcomes were also considered.

Results: Patients treated with tranexamic acid showed significant reductions in postoperative bleeding, both in terms of the amount collected during the first 4 postoperative hours (median $307 \mathrm{~mL}$, interquartile range $253-361 \mathrm{~mL}$ in the placebo group vs median $211 \mathrm{~mL}$, interquartile range $108-252 \mathrm{~mL}$ in the treatment group, $P=.002$ ) and in terms of total bleeding (median $722 \mathrm{~mL}$, interquartile range $574-952 \mathrm{~mL}$ in the placebo group vs median $411 \mathrm{~mL}$, interquartile range 313-804 $\mathrm{mL}$ in the treatment group, $P=.04)$. Consequently, the number of patients transfused differed significantly between groups (21 patients [72.4\%] in the placebo group vs 13 [44.8\%] in the treatment group, $P=.033$ ). Patients in the treatment group showed significant reductions in the total amount for the entire group of packed red cells transfused $(13,500 \mathrm{~mL}$ in the treatment group vs $28,000 \mathrm{~mL}$ in the placebo group, $P=.012)$ and in the total amount of allogeneic transfusions $(23,400$ $\mathrm{mL}$ in the treatment group vs $53,000 \mathrm{~mL}$ in the placebo group, $P=.024)$. No differences in perioperative thrombotic complications were found.

Conclusions: In this initial series of patients undergoing thoracic aortic surgery, tranexamic acid appeared effective in reducing perioperative bleeding, with a significant reduction in the need for allogeneic transfusions and without any increased risk of thrombotic complications.

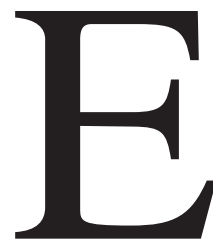

xcessive perioperative bleeding and the consequent increased need for allogeneic transfusions frequently complicate the outcome of patients undergoing thoracic aortic surgery. This bleeding is due to extended surgical dissection, the fragile tissues of the diseased aorta, and changes in coagulation processes related to cardiopulmonary bypass (CPB) and deep hypothermia and circulatory arrest (DHCA). ${ }^{1,2}$ The use of drugs with hemostatic properties has been widely addressed 
as a strategy to reduce perioperative bleeding in cardiac operations. ${ }^{3}$ Previously published studies have systematically evaluated in patients undergoing thoracic aortic surgery the hemostatic effects of aprotinin, a nonspecific serine protease inhibitor with antifibrinolytic properties. There is a lack, however, of prospective, placebo-controlled studies involving such drugs as $\epsilon$-aminocaproic acid and tranexamic acid, two synthetic antifibrinolytic drugs with demonstrated efficacy in reducing perioperative bleeding and allogeneic transfusions in cardiac surgery. ${ }^{4}$

In our institution, as a consequence of previously published studies, we routinely administer tranexamic acid to patients undergoing cardiac operations. 5,6 The aim of this study was to evaluate the effects of tranexamic acid on perioperative bleeding and allogeneic transfusions also in patients submitted to elective thoracic aortic surgery.

\section{Methods}

After institutional review board approval was obtained, along with informed consent from each patient, from January 1, 2000, to May 31,2001 , a total of 60 consecutive patients scheduled in our institution for elective thoracic aortic surgery were enrolled in the study. Exclusion criteria were as follows: advanced chronic renal insufficiency (creatinine $>2 \mathrm{mg} / \mathrm{dL}$ ), active chronic hepatitis or cirrhosis, and history of hematologic disorders. On the basis of these criteria, 1 patient was not included in the study (chronic renal insufficiency with preoperative creatinine of $3.5 \mathrm{mg} / \mathrm{dL}$ ). Preoperative treatment with aspirin or anticoagulant was not a contraindication to the enrollment in the trial.

A standardized protocol for anesthesia was applied. Premedication was obtained with intramuscularly administered morphine $(0.1 \mathrm{mg} / \mathrm{kg})$ and scopolamine $(0.5 \mathrm{mg})$. Induction and maintenance of anesthesia were performed with propofol, midazolam, and fentanyl, with nitrous oxide and isoflurane as needed. Muscle relaxation was obtained with pancuronium bromide.

\section{Surgical Protocol}

Tables 1 and 2 summarize the aortic pathologic conditions and the interventions performed in the two groups of patients. All the patients were operated on through a full median sternotomy, with the exception of 2 patients with descending thoracic aortic aneurysm, 1 per group, who underwent the only replacement of the descending thoracic aorta through a left thoracotomy performed in the fourth intercostal space. Most patients had disease of the aortic root, and a combined operation on the aortic valve and ascending aorta was performed. A total of 6 patients (3 patients per group) required DHCA, 5 because of surgery involving the aortic arch and 1 because of surgery on a calcified ascending aorta. Before arterial cannulation (aorta or femoral artery), full heparinization was obtained $(3 \mathrm{mg} / \mathrm{kg}$ ), and additional heparin was administered to maintain a celite activated coagulation time 480 seconds or higher (Actalyke; Helena Laboratories, Beaumont, Tex). The circuit for extracorporeal circulation comprised a roller pump (SC Stockert; Stockert Instrumente GmbH, München, Germany), which guaranteed a nonpulsatile blood flow, and a hollow-fiber membrane oxygenator (Affinity; Dideco, Mirandola, Italy). Priming of the
TABLE 1. Diagnoses of thoracic aorta disease

\begin{tabular}{|c|c|c|c|c|}
\hline & \multicolumn{2}{|c|}{$\begin{array}{c}\text { Placebo group } \\
(\mathbf{n}=\mathbf{3 0})\end{array}$} & \multicolumn{2}{|c|}{$\begin{array}{c}\text { Tranexamic } \\
\text { acid group } \\
(\mathbf{n}=\mathbf{3 0})\end{array}$} \\
\hline & No. & $\%$ & No. & $\%$ \\
\hline \multicolumn{5}{|l|}{ Aneurysm (no.) } \\
\hline Ascending aorta & 23 & 76.7 & 24 & 80 \\
\hline $\begin{array}{l}\text { Ascending aorta } \\
\text { and aortic arch }\end{array}$ & 1 & 3.3 & 2 & 6.7 \\
\hline Total & 24 & 80 & 26 & 86.7 \\
\hline \multicolumn{5}{|l|}{ Dissection (no.) } \\
\hline Type I & 1 & 3.3 & 1 & 3.3 \\
\hline Type II & 4 & 13.3 & 2 & 6.7 \\
\hline Type IIIb & 1 & 3.3 & 1 & 3.3 \\
\hline Total & 6 & 20 & 4 & 13.3 \\
\hline
\end{tabular}

Dissection types follow the DeBakey classification of aortic dissection (Ann Surg. 1955;162:586).

circuit consisted of $1700 \mathrm{~mL}$ of a balanced crystalloid and colloid solution (1300 mL Ringer lactate, $250 \mathrm{~mL} \mathrm{18 \%} \mathrm{mannitol,} \mathrm{and} 150$ $\mathrm{mL}$ plasma expander). Myocardial protection during aortic crossclamping was achieved with cold blood cardioplegia. DHCA was achieved with standardized methods, and in these cases cerebral protection was performed through retrograde cerebral perfusion. At the end of $\mathrm{CPB}$, heparin was antagonized with protamine sulfate (1:1 ratio); if needed, additional protamine was administered in 50-mg incremental doses to obtain an activated coagulation time value equal to or shorter than the baseline. A cell-saver circuit (Compact Advanced; Dideco) was used to recoup blood from the operative field and to process the blood remaining in the extracorporeal circuit after the cessation of CPB.

\section{Pharmacologic Protocol and Sampling Times}

The 60 patients were prospectively randomized, in a doubleblinded fashion, into two groups: a placebo control group (30 patients), who received an infusion of saline solution, and a treatment group (30 patients), who received tranexamic acid (bolus of $1 \mathrm{~g}$ in 20 minutes after induction of anesthesia but before skin incision, and continuous infusion of $400 \mathrm{mg} / \mathrm{h}$ during the whole surgical time. An additional $500 \mathrm{mg}$ of the drug was added to the priming of CPB. The staffs of both the operating room and the intensive care unit were blinded to the treatment. The correct procedure was ensured by means of coded infusion syringes prepared by the pharmacy of our center.

Samples for evaluation of hemoglobin, hematocrit, platelet count, fibrinogen, prothrombin time, activated partial thromboplastin time, creatinine, creatine kinase, and creatine kinase MB isoenzyme were taken before the induction of anesthesia (time 1), on the patient's arrival in the intensive care unit (time 2), at 24 and 48 hours after the operation (times 3 and 4), and at discharge (time 5).

\section{Criteria for Allogeneic Transfusion and Surgical Reexploration}

A standardized intraoperative and postoperative protocol for transfusion of allogeneic products was applied. During CPB, packed 


\begin{tabular}{|c|c|c|c|c|}
\hline & \multicolumn{2}{|c|}{$\begin{array}{l}\text { Placebo group } \\
\quad(\mathrm{n}=30)\end{array}$} & \multicolumn{2}{|c|}{$\begin{array}{l}\text { Tranexamic acid group } \\
\qquad(\mathbf{n}=\mathbf{3 0})\end{array}$} \\
\hline & No. & $\%$ & No. & $\%$ \\
\hline Previous intervention on thoracic aorta & 3 & 10 & 3 & 10 \\
\hline Graft replacement of ascending aorta & 2 & 6.7 & 2 & 6.7 \\
\hline Bentall-DeBono technique & 5 & 16.7 & 4 & 13.3 \\
\hline Cabrol technique & 0 & 0 & 1 & 3.3 \\
\hline Separate replacement of aortic valve and ascending aorta & 9 & 30 & 11 & 36.7 \\
\hline Aortic valve replacement and ascending aorta reconstruction & 3 & 10 & 5 & 16.7 \\
\hline Aortic valve reconstruction and ascending aorta replacement & 7 & 23.3 & 4 & 13.3 \\
\hline $\begin{array}{l}\text { Aortic valve reconstruction and ascending aorta and aortic } \\
\text { arch replacement }\end{array}$ & 1 & 3.3 & 1 & 3.3 \\
\hline Aortic valve, ascending aorta, and aortic arch replacement & 2 & 6.7 & 1 & 3.3 \\
\hline Descending aorta replacement & 1 & 3.3 & 1 & 3.3 \\
\hline DHCA & 3 & 10 & 3 & 10 \\
\hline \multicolumn{5}{|l|}{ Combined procedures } \\
\hline Coronary artery bypass grafting & 4 & 13.3 & 3 & 10 \\
\hline $\begin{array}{l}\text { Coronary artery bypass grafting and mitral valve } \\
\text { replacement }\end{array}$ & 1 & 3.3 & 2 & 6.7 \\
\hline
\end{tabular}

red blood cells (PRBCs) were transfused if the hemoglobin value was less than $6.5 \mathrm{~g} / \mathrm{dL}$ and the hematocrit value was less than $20 \%$. After CPB and during the postoperative period, PRBCs were transfused if the hemoglobin value was less than $8 \mathrm{~g} / \mathrm{dL}$ and the hematocrit value was less than $24 \%$. Fresh-frozen plasma (FFP) was infused after protamine administration if prothrombin time value was 1.5 times the baseline and there was microvascular bleeding. Platelet concentrate (PLTC) was transfused in the presence of microvascular bleeding and a platelet count less than 50,000 cells $/ \mathrm{mm}^{3}$. The total amount of allogeneic blood products transfused in each group was calculated as the sum of the single units: 1 bag of PRBCs was $300 \mathrm{~mL}, 1$ bag of FFP was $500 \mathrm{~mL}$, and one unit of PLTC was $50 \mathrm{~mL}$.

Blood loss was recorded during the first 24 hours. We defined excessive bleeding as a total amount greater than $600 \mathrm{~mL} / 24 \mathrm{~h}$. Chest drains were removed when bleeding was less than $100 \mathrm{~mL}$ in the last 4 hours. Surgical reexploration was considered when bleeding in the first 2 hours was greater than $300 \mathrm{~mL} / \mathrm{h}$ or if it was greater than $200 \mathrm{~mL} / \mathrm{h}$ for 4 consecutive hours, with normal coagulation data.

\section{Postoperative Evaluation}

As a possible consequence of antifibrinolytic therapy, the following thrombotic complications were recorded during the first 24 postoperative hours: myocardial infarction (new Q waves on electrocardiogram, creatine kinase MB isoenzyme to creatine kinase ratio greater than $10 \%$, troponin I value greater than $0.1 \mathrm{ng} / \mathrm{dL}$ ), acute renal insufficiency (creatinine value twice the baseline or need for dialysis), major neurologic dysfunction (transient ischemic attack or stroke), deep venous thrombosis, and pulmonary embolism.

\section{Statistical Analysis}

The trial was designed to detect a difference between the groups of $200 \mathrm{~mL}$ in postoperative bleeding with an SD of $250 \mathrm{~mL}$. This design was based on data emerging from a previous study. ${ }^{5}$ To achieve significance, a minimum of 25 patients per group was required, with a one-tailed $\alpha$ error of .05 and a power of $80 \%$. To test the normality of the distribution of the continuous variables, the Kolmogorov-Smirnov test was performed. The normally distributed data at each time were compared between the groups with a 2-tailed unpaired Student $t$ test and expressed as mean $\pm \mathrm{SD}$. Nonnormally distributed variables were compared by Mann-Whitney $U$ test and expressed as median and interquartile range (25th75 th percentiles). Categoric data were analyzed with the $\chi^{2}$ test or the Fisher exact test as appropriate. Two-way analysis of variance with repeated measures on one factor was used to evaluate the main effect of group on the hematologic variables, the effect of the time, and the group-time interaction. Data were analyzed with the SPSS 6.0 statistical package (SPSS Inc, Chicago, Ill).

\section{Results}

Of the 60 patients enrolled, 2 patients did not complete the study. They were excluded from statistical analysis. These two patients died in the operating room, both of cardiogenic shock refractory to maximal inotropic support. One patient in the control group, with ascending aorta aneurysm and aortic valve insufficiency, underwent separate aortic valve and ascending aorta substitution, and one patient in the tranexamic acid group, with a history of coronary disease and aneurysm of ascending aorta with aortic valve insufficiency, underwent combined intervention of coronary revascularization, aortic valve reconstruction, and ascending aorta substitution. The remaining 58 patients were considered for statistical analysis. Their demographic and preoperative hematologic data are shown in Tables 3 and 4. No differences between the groups emerged. As evidenced in Table 5, the two groups were also homogeneous with re- 
TABLE 3. Demographic characteristics

\begin{tabular}{|c|c|c|c|}
\hline & $\begin{array}{l}\text { Placebo group } \\
(\mathbf{n}=29)\end{array}$ & $\begin{array}{c}\text { Tranexamic acid } \\
\text { group }(n=29)\end{array}$ & $P$ value \\
\hline Age $(y$, mean $\pm S D)$ & $63 \pm 11$ & $59 \pm 13$ & .21 \\
\hline Male sex (no.) & $19(65.5 \%)$ & $23(79.3 \%)$ & .24 \\
\hline Height (cm, mean $\pm \mathrm{SD}$ ) & $168 \pm 10$ & $168 \pm 11$ & .97 \\
\hline Weight $(\mathrm{kg}$, mean $\pm \mathrm{SD})$ & $76 \pm 17$ & $74 \pm 14$ & .66 \\
\hline $\begin{array}{l}\text { Baseline left ventricular ejection fraction } \\
\quad(\% \text {, mean } \pm \text { SD })\end{array}$ & $54 \pm 11$ & $58 \pm 9$ & .12 \\
\hline $\begin{array}{l}\text { New York Heart Association functional class } \\
\text { (median and interquartile range) }\end{array}$ & $2(2-3)$ & $2(2-3)$ & .54 \\
\hline Previous cardiac operation (no.) & $7(24.1 \%)$ & $9(31.0 \%)$ & .56 \\
\hline Preoperative aspirin (no.) & $5(17.2 \%)$ & $6(20.7 \%)$ & .94 \\
\hline Preoperative anticoagulant (no.) & $6(20.7 \%)$ & $6(20.7 \%)$ & $>.999$ \\
\hline
\end{tabular}

The $t$ test, Mann-Whitney $U$ test, $\chi^{2}$ test, or Fisher exact test was used as appropriate to determine $P$ values.

TABLE 4. Baseline hematochemical data

\begin{tabular}{|c|c|c|c|}
\hline & $\begin{array}{c}\text { Placebo group } \\
(\mathrm{n}=29)\end{array}$ & $\begin{array}{c}\text { Tranexamic acid } \\
\text { group }(\mathbf{n}=29)\end{array}$ & $P$ value \\
\hline Hemoglobin $(\mathrm{g} / \mathrm{dL}$, mean $\pm \mathrm{SD})$ & $14 \pm 1.3$ & $14 \pm 1.6$ & .83 \\
\hline Hematocrit $(\%$, mean \pm SD) & $42.2 \pm 4.1$ & $41.2 \pm 4.5$ & .57 \\
\hline Platelet count $\left(10^{3}\right.$ cells $/ \mathrm{mm}^{3}$, mean $\left.\pm \mathrm{SD}\right)$ & $196 \pm 41$ & $190 \pm 51$ & .66 \\
\hline Fibrinogen (mg/dL, median and interquartile range) & $394(291-446)$ & $374(320-450)$ & .68 \\
\hline Prothrombin time $(\%$, median and interquartile range) & $86(70-100)$ & $94(78-100)$ & .54 \\
\hline $\begin{array}{l}\text { Activated partial thromboplastin time (s, median and } \\
\text { interquartile range) }\end{array}$ & $34(31-36)$ & $35(30-37)$ & .75 \\
\hline Activated coagulation time $(s$, mean $\pm S D)$ & $151 \pm 30$ & $146 \pm 27$ & .42 \\
\hline Creatinine $(\mathrm{mg} / \mathrm{dL}$, mean $\pm \mathrm{SD})$ & $1.0 \pm 0.3$ & $0.9 \pm 0.2$ & .11 \\
\hline Creatine kinase (U/L, median and interquartile range) & $65.5(49-85)$ & $73(60.5-100)$ & .17 \\
\hline
\end{tabular}

The $t$ test or Mann-Whitney $U$ test was used as appropriate to determine $P$ values.

spect to the operative data. Table 6 summarizes postoperative bleeding and perioperative allogeneic transfusions. Significant differences were found in bleeding during the first 4 postoperative hours and in the total amount of blood loss recorded during the first 24 postoperative hours, both of which were significantly higher in the placebo group. The percentage of patients who showed excessive bleeding was significantly higher in the placebo control group $(62.1 \%$ vs $34.5 \%$ in treatment group, $P=.036$ ). Consequently, the number of patients requiring allogeneic transfusions was also significantly higher in the placebo group (Table 6). In particular, there were significant differences in terms of the total amount of perioperative PRBC transfusion. The number of patients transfused with FFP and the total amount of FFP transfused was higher in the placebo control group, but without reaching statistical significance. No differences were recorded in terms of PLTC transfused. All the hematologic variables considered changed significantly with time, but no significant differences were found between the groups or as a time-group interaction (data not shown). Finally, as evidenced in Table 7, no differences were found in major complications during the first 24 postoperative hours. Two patients in each group required surgical reexploration for bleeding: a surgical source was found in 2 patients (1 per group). The other two patients showed diffuse bleeding necessitating transfusion of FFP and PLTC. Four patients died during the postoperative period: 2 patients in the placebo group because of low cardiac outputrelated organ dysfunction, 1 patient in the tranexamic acid group because of respiratory insufficiency, and 1 patient in the tranexamic acid group because of multiple organ failure after low cardiac output.

\section{Discussion}

To the best of our knowledge, this is the first study in which the hemostatic properties of a synthetic antifibrinolytic drug have been tested in a prospective, randomized, doubleblinded manner on patients undergoing thoracic aortic operations. This type of surgery is characterized by high incidence of perioperative bleeding, and the reasons are complex. Preoperative reasons include the fragility of the diseased aortic tissues and alterations in coagulation related to excessive fibrinolysis as a consequence of the exposure of the blood to thromboplastin within atherosclerotic plaque in 


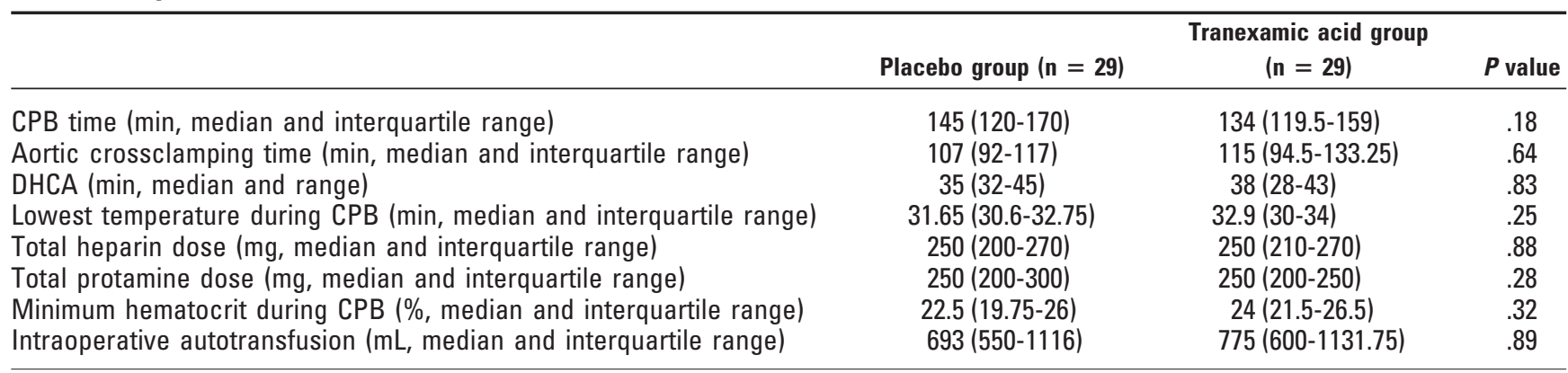

The Mann-Whitney $U$ test was used as appropriate to determine $P$ values. Lower temperature during CPB refers to the patients operated on without DHCA

TABLE 6. Postoperative bleeding and perioperative allogeneic transfusions

\begin{tabular}{|c|c|c|c|}
\hline & $\begin{array}{l}\text { Placebo group } \\
\quad(n=29)\end{array}$ & $\begin{array}{l}\text { Tranexamic acid } \\
\text { group }(n=29)\end{array}$ & $P$ value \\
\hline \multicolumn{4}{|l|}{ Bleeding } \\
\hline Bleeding in $1 \mathrm{st} 4 \mathrm{~h}$ (mL, median and interquartile range) & $307(253-361)$ & $211(108-252)$ & .002 \\
\hline Total bleeding (mL, median and interquartile range) & $722(574-952)$ & $411(313-804)$ & .04 \\
\hline Excessive bleeding (no.) & $18(62.1 \%)$ & $10(34.5 \%)$ & .04 \\
\hline \multicolumn{4}{|l|}{ PRBCs in operating room } \\
\hline Total volume transfused (mL) & 3300 & 1200 & .22 \\
\hline Patients transfused (no.) & 5 & 2 & \\
\hline \multicolumn{4}{|l|}{ Total PRBCs } \\
\hline Total volume transfused $(\mathrm{mL})$ & 24,600 & 9600 & .01 \\
\hline Patients transfused (no.) & 19 & 11 & \\
\hline \multicolumn{4}{|l|}{ FFP in operating room } \\
\hline Total volume transfused $(\mathrm{mL})$ & 2000 & 2000 & $>.999$ \\
\hline Patients transfused (no.) & 2 & 2 & \\
\hline \multicolumn{4}{|l|}{ Total FFP } \\
\hline Total volume transfused $(\mathrm{mL})$ & 28,000 & 13,000 & .12 \\
\hline Patients transfused (no.) & 15 & 9 & \\
\hline \multicolumn{4}{|l|}{ PLTC in operating room } \\
\hline Total volume transfused $(\mathrm{mL})$ & 0 & 300 & .32 \\
\hline Patients transfused (no.) & 0 & 1 & \\
\hline \multicolumn{4}{|l|}{ Total PLTC } \\
\hline Total volume transfused $(\mathrm{mL})$ & 400 & 300 & .9 \\
\hline Patients transfused (no.) & 1 & 1 & \\
\hline \multicolumn{4}{|l|}{ All blood products } \\
\hline Total volume transfused $(\mathrm{mL})$ & 53,000 & 23,400 & .02 \\
\hline Patients transfused (no.) & $21(72.4 \%)$ & $13(44.8 \%)$ & .03 \\
\hline
\end{tabular}

The Mann-Whitney $U$ test, $\chi^{2}$ test, or Fisher exact test was used as appropriate to determine $P$ values. Excessive bleeding was considered to be more than $600 \mathrm{~mL}$ in the first 24 hours.

patients with aortic dissection or aneurysm rupture. ${ }^{7}$ Operative causes of bleeding include the large surgical surfaces, the use of CPB, and DHCA. ${ }^{8,9}$

During cardiac operations performed with $\mathrm{CPB}$, both the intrinsic pathway, through the contact of the blood with the foreign surfaces of the circuit for extracorporeal circulation, and the extrinsic pathway, through the activation of tissue factor, are intensively stimulated. ${ }^{10,11}$ The wide surgical dissection areas determine activation of the extrinsic pathway through the release of tissue factor by endothelial cells. Hypothermia induces profound alteration of the coagulation system through speed reduction in enzymatic activity and alteration of platelet morphology, with decreased platelet aggregation following the reduction of thromboxane release and plasmin-related degradation of glycoprotein $\mathrm{Ib}$ receptors. ${ }^{2,9}$ Circulatory arrest determines stagnation of the blood into the vascular bed, and through the production of tissue plasminogen activator by endothelial cells, thrombin is produced and the fibrinolytic system is induced. There is also the activation of protein $\mathrm{C}$, which exerts a potent anticoagulant effect through the inhibition of factors Va and VIIIa and the inactivation of plasminogen activator inhibitor types I and III, thus promoting fibrinolysis. ${ }^{8}$ All these factors contribute to the complex hemostatic alterations and the 
TABLE 7. Outcomes and perioperative complications

\begin{tabular}{|c|c|c|c|}
\hline & $\begin{array}{l}\text { Placebo group } \\
(\mathbf{n}=29)\end{array}$ & $\begin{array}{l}\text { Tranexamic acid } \\
\text { group }(\mathbf{n}=29)\end{array}$ & $P$ value \\
\hline Surgical reexploration for bleeding (no.) & $2(6.9 \%)$ & $2(6.9 \%)$ & $>.999$ \\
\hline Intubation time (h, median and interquartile range) & $8.5(5.5-17)$ & $7(5-10)$ & .14 \\
\hline \multicolumn{4}{|l|}{ Hospital stay (d, median and interquartile range) } \\
\hline Intensive care unit stay & $1(1-2)$ & $1(1-2)$ & .47 \\
\hline Postoperative hospital stay & $8(7-11)$ & $7(6-8)$ & .19 \\
\hline \multicolumn{4}{|l|}{ Cardiac complications (no.) } \\
\hline Low cardiac output necessitating major inotropic therapy & $6(20.7 \%)$ & $5(17.2 \%)$ & .74 \\
\hline Atrial fibrillation & $5(17.2 \%)$ & $6(20.7 \%)$ & .74 \\
\hline Heart block requiring pacemaker implantation & $2(6.9 \%)$ & $1(3.4 \%)$ & .5 \\
\hline Myocardial infarction & $1(3.4 \%)$ & $1(3.4 \%)$ & $>.999$ \\
\hline \multicolumn{4}{|l|}{ Renal failure (no.) } \\
\hline Creatinine double baseline & $5(17.2 \%)$ & $4(13.8 \%)$ & .72 \\
\hline Dialysis & $1(3.4 \%)$ & $1(3.4 \%)$ & $>.999$ \\
\hline \multicolumn{4}{|l|}{ Neurologic complications (no.) } \\
\hline Minor & $1(3.4 \%)$ & $2(6.9 \%)$ & .5 \\
\hline Stroke & $2(6.9 \%)$ & $1(3.4 \%)$ & .5 \\
\hline Pulmonary embolism (no.) & $0(0 \%)$ & $0(0 \%)$ & $>.999$ \\
\hline Postoperative death (no.) & $2(6.9 \%)$ & $2(6.9 \%)$ & $>.999$ \\
\hline
\end{tabular}

derived abnormal perioperative bleeding frequently seen in patients undergoing thoracic aortic surgery.

The principal consequence of excessive perioperative blood loss is an increased need for allogeneic transfusions, with the derived risks of immunologic reactions and viral infectious diseases such as hepatitis $\mathrm{C}$ and acquired immunodeficiency syndrome. ${ }^{12}$ In addition, patients with excessive bleeding are exposed to a higher rate of surgical reexploration, with consequent increased risks of morbidity and mortality. ${ }^{13}$

A study by Svensson and colleagues ${ }^{14}$ demonstrated that patients undergoing thoracic aorta operations who did not receive allogeneic blood transfusions had better outcomes. Methods of reducing allogeneic transfusions, such as preoperative autologous blood donation, intraoperative isovolemic hemodilution, intraoperative blood salvage and reinfusion, and the use of drugs with hemostatic properties, have therefore received great attention of late. ${ }^{15}$ In particular, many previously published randomized, double-blind, prospective trials have evaluated the hemostatic effects of aprotinin in aortic surgery, particularly when performed with DHCA, ${ }^{16-20}$ whereas no one has considered the synthetic antifibrinolytic drugs $\epsilon$-aminocaproic acid and tranexamic acid. Aprotinin is a product naturally derived from bovine lung with nonspecific antiprotease and antifibrinolytic properties, and it has a complex action on the coagulation system. ${ }^{21}$ Even though significant reductions in perioperative bleeding and allogeneic transfusions have been reported with this drug, in various reports its use in aortic surgery with DHCA has been related to an increased risk of thrombotic complications, such as renal insufficiency, myo- cardial infarction, and death. ${ }^{20,22-24}$ For these reasons the use of aprotinin continues to be debated.

Tranexamic acid and $\epsilon$-aminocaproic acid are two lowcost synthetic antifibrinolytic drugs that prevent the plasmin-mediated conversion of fibrinogen to fibrinogen split products through the inhibition of the lysine-binding sites on plasminogen and fibrinogen, thus blocking fibrinolysis. ${ }^{25}$ They also exert a protective effect on platelets through the inhibition of plasminogen and plasmin at platelets, thus blocking the activation of platelets as a result of local plasmin concentration. ${ }^{26}$ The use of $\epsilon$-aminocaproic acid in thoracic aortic surgery has been proposed by various authors. ${ }^{14,15,27,28}$ In a retrospective study, Eaton and coworkers $^{27}$ compared aprotinin with $\epsilon$-aminocaproic acid in 49 patients undergoing aortic surgery involving DHCA. They concluded that the two drugs appeared equally efficacious in reducing perioperative bleeding and transfusion requirement. Svensson and colleagues ${ }^{14,15}$ and Cohn and cowork$\mathrm{ers}^{28}$ proposed the administration of $\epsilon$-aminocaproic acid among potential strategies to reduce the bleeding associated with thoracic aortic surgery.

Until now no study has considered tranexamic acid as an antifibrinolytic drug in thoracic aorta surgery. In our institution, as a consequence of the results of previously published studies, tranexamic acid is routinely administered to all patients undergoing cardiac surgery with $\mathrm{CPB},{ }^{5,6}$ and recently it has also been administered to patients undergoing beating-heart coronary operations without extracorporeal circulation. ${ }^{29} \mathrm{We}$ therefore elected to evaluate the hemostatic effects of tranexamic acid in patients undergoing thoracic aortic surgery. Our most important result was the 
significant reduction in perioperative bleeding, and consequently in the amount of allogeneic transfusions, among the patients treated with tranexamic acid. In particular we observed a reduction of about $30 \%$ in the number of patients who required at least one type of allogeneic blood product. The antihemorrhagic effects of the drug are clearly demonstrated by the reduction of bleeding, particularly during the first 4 postoperative hours when the drug is present in the blood in therapeutic concentrations..$^{25}$ In addition, the quantity of FFP transfused was clearly greater in the placebo group, although this difference did not reach statistical significance, probably because of the relatively small number of patients enrolled.

Another important aspect of the use of antifibrinolytic drugs is the theoretic possibility of an increased rate of thrombotic complications. In this relatively small series of patients we did not observe any difference between treated and untreated patients, and the occurrences of thrombotic complications in both groups were similar to those described in previous published studies. ${ }^{30,31}$ One patient in the tranexamic acid group with a history of associated coronary disease died intraoperatively of cardiogenic shock; in this case an autopsy was not performed, so conclusions regarding a possible myocardial ischemia induced by a thrombotic complication related to tranexamic acid are not possible. Further studies on a greater number of patients with the primary outcomes of morbidity and mortality may lead to more precise answers.

One limitation of the study is the relatively small number of patients operated on with DHCA. Because of the profound alterations of coagulation seen with DHCA, this group could benefit greatly from therapy with tranexamic acid. This may be an interesting area for further studies. Another limitation is that this was a clinical study, with no specific laboratory evaluations of platelet function, coagulation, and fibrinolysis. Because of this, no conclusions regarding the functional aspect of tranexamic acid in this type of surgery are possible. Additional studies may compare tranexamic acid with the principal hemostatic drugs currently used in cardiac surgery, such as aprotinin and $\epsilon$-aminocaproic acid, to examine their different biochemical effects on coagulation and the fibrinolytic system.

\section{Conclusions}

To conclude, in this initial series of patients undergoing operations involving the thoracic aorta, the use of tranexamic acid led to a significant reduction in perioperative bleeding and consequently in the need for allogeneic transfusions. Further studies with larger numbers of patients are required to confirm these initial observations and to exclude the theoretic risk of an increased rate of thrombotic complications.

\section{References}

1. Woodman RC, Harker LA. Bleeding complications associated with cardiopulmonary bypass. Blood. 1990;76:1680-97.

2. Westaby S. Coagulation disturbance in profound hypothermia. Semin Thorac Cardiovasc Surg. 1997;9:246-56.

3. Levi M, Cromheecke ME, de Jonge E, Prins MH, de Mol BJ, Briet E, et al. Pharmacological strategies to decrease excessive blood loss in cardiac surgery: a meta-analysis of clinically relevant endpoints. Lancet. 1999;354:1940-7.

4. Westaby S. Anti-fibrinolytic therapy in thoracic aortic surgery. Ann Thorac Surg. 1999;67:1983-5.

5. Casati V, Guzzon D, Oppizzi M, Cossolini M, Torri G, Calori G, et al. Hemostatic effects of aprotinin, tranexamic acid and $\epsilon$-aminocaproic acid in primary cardiac surgery. Ann Thorac Surg. 1999;68:2252-7.

6. Casati V, Guzzon D, Oppizzi M, Bellotti F, Franco A, Gerli C, et al. Tranexamic acid compared with high-dose aprotinin in primary elective heart operations: effects on perioperative bleeding and allogeneic transfusions. J Thorac Cardiovasc Surg. 2000;120:520-7.

7. Fisher DF, Yawn DH, Crawford ES. Preoperative disseminated intravascular coagulation associated with aortic aneurysm. Arch Surg. 1983;118:1252-5.

8. Stern DM, Kaiser E, Naworth PP. Regulation of the coagulation system by vascular endothelial cells. Hemostasis. 1988;18:202-14.

9. Lu H, Soria C, Cramer EM, Soria J, Maclouf J, Perrot JY, et al. Temperature dependence of plasmin-induced activation or inhibition of human platelets. Blood. 1991;77:996-1005.

10. Heimark RL, Kurachi K, Fujikawa K, Davie EW. Surface activation of blood coagulation, fibrinolysis and kinin formation. Nature. 1980; 286:456-60.

11. Boisclair MD, Lane DA, Philippou H, Esnouf P, Sheikh S, Hunt B, et al. Mechanisms of thrombin generation during surgery and cardiopulmonary bypass. Blood. 1993;82:3350-7.

12. Goodnough LT, Brecher ME, Kanter MH, AuBuchon JP. Transfusion medicine. First of two parts-blood transfusion. $N$ Engl J Med. 1999;340:438-47.

13. Dacey LJ, Munoz JJ, Baribeau YR, Johnson ER, Lahey SJ, Leavitt BJ, et al. Reexploration for hemorrhage following coronary artery bypass grafting: incidence and risk factors. Arch Surg. 1998;113:442-7.

14. Svensson LG, Sun J, Nadolny E, Kimmel WA. Prospective evaluation of minimal blood use for ascending aorta and aortic arch operations. Ann Thorac Surg. 1995;59:1501-8.

15. Svensson LG. How to obtain hemostasis after aortic surgery. Ann Thorac Surg. 1999;67:1981-2.

16. Seigne PW, Shorten GD, Johnson RG, Comunale ME. The effects of aprotinin on blood product transfusion associated with thoracic aortic surgery requiring deep hypothermic circulatory arrest. J Cardiothorac Vasc Anesth. 2000;14:676-81.

17. Ehrlich M, Grabenwöger M, Cartes-Zumelzu F, Luckner D, Kovarik J, Laufer G, et al. Operation on the thoracic aorta and hypothermic circulatory arrest: is aprotinin safe? J Thorac Cardiovasc Surg. 1998; 115:220-5

18. Okita Y, Takamoto S, Ando M, Morota T, Yamaki F, Matsukawa R, et al. Coagulation and fibrinolysis system in aortic surgery under deep hypothermic circulatory arrest with aprotinin. Circulation 1997;96 Suppl:II376-81.

19. Goldstein DJ, DeRosa CM, Mongero LB, Weinberg AD, Michler RE, Rose EA, et al. Safety and efficacy of aprotinin under conditions of deep hypothermia and circulatory arrest. J Thorac Cardiovasc Surg. 1995;110:1615-22.

20. Westaby S, Forni A, Dunning J, Giannopoulos N, O'Regan D, Drossos $\mathrm{G}$, et al. Aprotinin and bleeding in profoundly hypothermic perfusion. Eur J Cardiothorac Surg. 1994;8:82-6.

21. Davis R, Whittington R. Aprotinin: a review of its pharmacology and therapeutic efficacy in reducing blood loss associated with cardiac surgery. Drugs. 1995;49:954-83.

22. Alvarez JM, Goldstein J, Mezzatesta J, Flanagan B, Dodd M. Fatal intraoperative pulmonary thrombosis after graft replacement of an aneurysm of the arch and descending aorta in association with deep hypothermic circulatory arrest and aprotinin therapy. J Thorac Cardiovasc Surg. 1998;115:723-4.

23. Sundt TM, Kouchoukos NT, Saffitz JE, Murphy SF, Wareing TH, 
Stahl DJ. Renal dysfunction and intravascular coagulation with aprotinin and hypothermic circulatory arrest. Ann Thorac Surg. 1993;55: 1418-24.

24. Saffitz JE, Stahl DJ, Sundt TM, Wareing TH, Kouchoukos NT. Disseminated intravascular coagulation after administration of aprotinin in combination with deep hypothermic circulatory arrest. Am J Cardiol. 1993;72:1080-2.

25. Verstraete M. Clinical application of inhibitor of fibrinolysis. Drugs. 1985;29:236-61.

26. Soslau G, Horrow J, Brodsky I. Effect of tranexamic acid on platelet ADP during extracorporeal circulation. Am J Hematol. 1991;38:113-9.

27. Eaton MP, Deeb GM. Aprotinin versus $\epsilon$-aminocaproic acid for aortic surgery using deep hypothermic circulatory arrest. J Cardiothorac Vasc Anesth. 1998;12:548-52.
28. Cohn LH, Rizzo RJ, Adams DH, Aranki SF, Couper GS, Beckel N, et al. Reduced mortality and morbidity for ascending aortic aneurysm resection regardless of cause. Ann Thorac Surg. 1996;62: 463-8.

29. Casati V, Gerli C, Franco A, Torri G, D’Angelo A, Benussi S, et al. Tranexamic acid in off-pump coronary surgery: a preliminary, randomized, double-blind, placebo controlled study. Ann Thorac Surg. 2001;72:470-5.

30. Kouchoukos NT, Wareing TH, Murphy SF, Perrillo JB. Sixteen-year experience with aortic root replacement: results of 172 operations. Ann Surg. 1991;214:308-20.

31. Svensson LG, Crawford ES, Hess KR, Coselli JS, Safi HJ. Composite valve graft replacement of the proximal aorta: comparison of techniques in 348 patients. Ann Thorac Surg. 1992;54:427-39.

Access to The Journal of Thoracic and Cardiovascular Surgery Online is reserved for print subscribers!

Full-text access to The Journal of Thoracic and Cardiovascular Surgery Online is available for all print subscribers. To activate your individual online subscription, please visit The Journal of Thoracic and Cardiovascular Surgery Online, point your browser to http://www.mosby.com/itcvs, follow the prompts to activate your online access, and follow the instructions. To activate your account, you will need your subscriber account number, which you can find on your mailing label (note: the number of digits in your subscriber account number varies from 6 to 10). See the example below in which the subscriber account number has been circled:

\section{Sample mailing label}

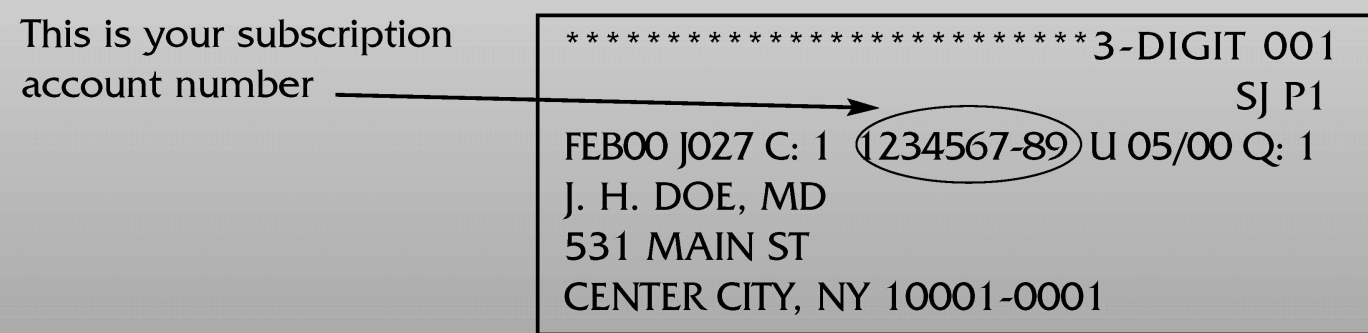

Personal subscriptions to The Journal of Thoracic and Cardiovascular Surgery Online are for individual use only and may not be transferred. Use of The Journal of Thoracic and Cardiovascular Surgery Online is subject to agreement to the terms and conditions as indicated online. 